\title{
Application of the bespoke solid-phase extraction protocol for extraction of physiologically-active compounds from vegetable oils
}

\author{
Eman Alghamdi a, b*, Sergey Piletsky a , Elena Piletska ${ }^{a}$ \\ a. Department of Chemistry, College of Science and Engineering, University of Leicester, Leicester, LE1 7RH, United Kingdom \\ ${ }^{b}$ Department of Chemistry, College of Science, University of King Abdul Aziz, Jeddah, Kingdom of Saudi Arabia \\ *Corresponding author-E-mail: ea232@leicester.ac.uk
}

\section{ABSTRACT}

A possibility of harvesting the physiologically-active compounds from the vegetable oils using bespoke resin and optimised solid-phase extraction (SPE) purification method is demonstrated. The paper describes the application of SPE protocol, which was originally developed, using sunflower oil as model biomass, for extraction of the valuable compounds from sesame, wheat germ, palm, olive and soybean oils. As a result, the extraction of three free fatty acids (palmitic, oleic and linoleic), $\alpha$-tocopherol and three phytosterols (campesterol, stigmasterol and $\beta$-sitosterol) from six vegetable oils have been demonstrated. The comparison between the published data on the amount of the analysed compounds in the corresponding vegetable oils and presented here extraction results confirm that the developed method allowed not only quantitatively extract the physiologically-active components from various vegetable oils without any pre-treatment but also was reproducible, cost-effective and ecologicallyconscious as consumed smaller volumes of organic solvents than commonly used protocols.

Keywords: Solid-phase extraction (SPE); Vegetable oil; Free fatty acids; Tocopherol; Phytosterols

\section{Introduction}

The vegetable oils, such as rapeseed, canola, soybean, sunflower and palm oils, are commonly used biomasses for production of biodiesel. Considering that biofuel is a renewable and ecologically-friendly source of energy, extra efforts should be made to lower the cost of biodiesel, which could be done "by increasing feedstock yields, developing novel technologies, and increasing economic return"[1]. It is known that vegetable oils consist of 95 to $98 \%$ of triacylglycerol and 2 to $5 \%$ of different groups of minor components such as hydrocarbons, tocopherols, phytosterols and their esters [2-4]. Triglycerides are the main components of vegetable oils which are used for the production of biodiesel through their transesterification reaction with methanol or ethanol in the presence of the alkali catalyst [5-7]. Unfortunately, all these minor components of the vegetable oils, which are typically valuable physiologically active compounds, are completely lost during the biofuel production process. It is possible to envisage that recovering the 'bioactives' before the biofuel production could have added value to the biofuel production and make the cost of biofuel lower or at least comparable with traditional fossil fuels.

Apart of added value through the recovery of valuable ingredients of the vegetable oils, removal of some of them, particularly, free fatty acids, could make the biodiesel production more effective by preventing their reaction with the alkali catalyst during transesterification reaction, which usually requires a great amount of alcohol to maintain the equilibrium of the reaction and produce more methyl esters $[5,6]$. It was observed that the presence of free fatty acids negatively affects the production of biodiesel from the vegetable oils resulting in the production of the soap and water, thus inhibiting the separation and purification processes of the biodiesel production [6, 7].

The most common fatty acids present in vegetable oils are palmitic, oleic and linoleic acids. Palmitic acid is the abundant saturated fatty acid that has numerous food and industrial applications. According to Mancini and co-workers, palmitic acid is an important constituent of such widely-used products as ice cream, toothpaste, candles and cosmetic products [8]. The oleic acid, mono-unsaturated fatty acids, is known for its reducing effect on the blood sugar levels and protection of the heart [9]. It was shown that linoleic acid, which is one of the main di-unsaturated fatty acids, can lower the triglyceride and cholesterol content of the cells, which leads to a reduction of the incidence of cardiovascular diseases [10]. 
Tocopherols, which are the representatives of vitamin E group, are typical examples of the minor components of the vegetable oils. Vitamin E compounds are most associated with antioxidant activity in the humans' body. One of the most known members of vitamin E group is $\alpha$-tocopherol [11-15]. The recent studies also indicated the importance of another member of the vitamin E family, $\gamma$-tocopherol. It is known that the main role of vitamin $E$ in the body is a reduction of peroxyl radicals. It was also proven that the presence of $\alpha$-tocopherol increases the bioavailability of $\gamma$-tocopherol [4]. Not surprising that the members of vitamin E group widely used in medicine, cosmetics, agriculture and food industry [16-21].

Other minor components of vegetable oils are triterpenes phytosterols (plant sterols). They have also drawn the attention of the researchers due to their bioactivity. It is known that phytosterols are present in the plants either in their free form or being either conjugated with fatty acids or glycosylated with hexose. Phytosterols have potential to reduce total serum cholesterol as well as LDL-cholesterol in the human body through the inhibition of the absorption of the dietary cholesterol and the reabsorption of excreted cholesterol to the bile in the enterohepatic cycle [17-19].

Many research endeavours have been made to develop efficient and economical procedures for extraction the minor physiologically active components from natural oil sources [20]. The most extraction methods of the minor components from oil involve saponification, liquid-liquid extraction and chromatography, which require pre-treatment steps before extraction from oil. All these processes also involve several further steps including solvent extraction, drying and reconstitution steps. Thus, the traditional extraction from oil is generating considerable volumes of chemical waste and are difficult to control $[21,22.10,13]$. Most of the bioactive compounds are sensitive to oxygen, light and long exposure to alkaline conditions, which must be taken into account in order to avoid the partial degradation of any of the minor components during their extraction.

One of the most effective and popular extraction technique and clean-up method is solid-phase extraction (SPE) in terms of its simplicity and limited use of organic solvents $[11,13,23-25]$. Nonetheless, it is important to underline that due to the complexity and high viscosity of oil matrices, the extraction of any compounds from natural oils is a very challenging task. There are very limited publications that present successful development of the Molecularly Imprinted Polymers as resins for extraction of oilsoluble pesticides [26-28]. SPE is performed using glass or plastic columns packed with a stationary phase. There are several types of commercial stationary phases which are suffer from poor stability towards some solvents, insufficient selectivity, limited reproducibility and restricted binding capacity, especially for polar compounds $[11,14,21]$. Therefore, due to the unavailability of effective commercial resins for extraction of such secondary metabolites from oil matrices, there is a demand for an economical, alternative stationary phase that is cost-effective and could, potentially, be suitable for industrial applications. The developed resin (RDP) in the current study is aimed for the extraction and purification of a group of minor components including free fatty acids, $\alpha$-tocopherol and some phytosterols from some vegetable oils. The advantages of RDPs that could make them appropriate for analytical and industrial applications are their low cost, reproducibility, group-selectivity towards the compounds having some common functionalities, compatibility with mass-manufacturing and high stability $[14,20,22]$. In this study, we would like to propose a protocol, which allows to "harvest" in one step several physiologically-active compounds from vegetable oils. The optimised protocol is using minimum volume of organic solvents in an environmentally-safe process.

\section{Materials and methods}

\subsection{Chemicals and reagents}

The unrefined and cold-pressed sunflower and sesame oils were purchased from Activecare (Amazon.co.uk). Palm oil was obtained from KTC (KTC Edibles, UK). Olive and soybeans oil were bought from the Food Marketplace through Amazon.com. Analytical standards originated from vegetable oils ( $\alpha$-tocopherol, mixture of phytosterols containing $46 \% \beta$-sitosterol, $24 \%$ campesterol and $16 \%$ stigmasterol) were purchased from Santa Cruz Biotechnology, UK and free fatty acids, including palmitic, oleic and linoleic acids were obtained from Aldrich, UK. Methanol, ethyl acetate, heptane, acetonitrile, 
$\mathrm{n}$-hexane, dichloromethane and acetic acid were obtained from Fisher Scientific, UK. All solvents were used without any purification and they all were of HPLC-quality grade. 1,1'-azobis (cyclohexane carbonitrile), methacrylic acid (MAA) and ethylene glycol dimethacrylate (EGDMA) were purchased from Aldrich, UK. Dimethyl formamide (DMF) was obtained from Acros Organics (UK).

\subsection{Equipment and analysis techniques}

1-mL SPE columns were packed with $200 \mathrm{mg}$ of the RDP and used in combination with a vacuum manifold (Supelco, UK). The analysis and quantification of the extracted components in the eluted samples was conducted using PerkinElmer gas chromatography-mass spectrometry set-up (PerkinElmer, TurboMass, UK). GC-MS was performed using a ZB-5 capillary column (30 m x $250 \mu \mathrm{m}$, I. D. - $0.25 \mathrm{~mm}$; Phenomenex, UK). Helium as a carrier gas was utilised under a flow-rate of $1 \mathrm{~mL} \mathrm{~min}{ }^{-1}$ at $200{ }^{\circ} \mathrm{C}$. The temperature of the GC oven was raised after a sample injection by $10^{\circ} \mathrm{C} \mathrm{min}^{-1}$ to $350^{\circ} \mathrm{C}$ and held for 3 min. For fatty acid analysis, it was used IR spectroscopy, (Spectrophotometer Avatar 370 FTIR Thermo Nicolet, UK).

\subsection{Synthesis of the RDP}

The composition of the polymer has been designed based on the results of the molecular modelling using the methacrylic acid (MAA) as a functional monomer that showed a high binding energy towards $\alpha$-tocopherol in previous research and ethylene glycol dimethacrylate (EGDMA) as a cross-linker. The syntheses of the polymer and optimisation of the SPE protocol has been described in details in the previously published work [29].

\subsection{Application the optimised SPE protocol to the vegetable oils}

The optimised protocol, which was applied to all tested oil, was based on previous research [29] as follows:

\subsubsection{Preparation of oil sample}

An aliquot of the oil was dissolved in heptane to the final concentration of $20 \%$. The standards solutions of palmitic, linoleic, oleic acids, $\alpha$-tocopherol and mixture of 3 phytosterols: campesterol, stigmasterol and $\beta$-sitosterol were prepared individually. Then $0.3 \mathrm{mg}$ of each standard solution was used to spike 1 $\mathrm{mL}$ of the oil solution in heptane.

\subsubsection{The SPE protocol conditions}

The SPE cartridges were packed with $200 \mathrm{mg}$ of RDP, conditioned with $1 \mathrm{~mL}$ of heptane, then, loaded with $1 \mathrm{~mL}$ of spiked oil sample and $1 \mathrm{~mL}$ of oil without spiking individually in two separate cartridges for each type of oil. After loading the cartridges were washed using $1 \mathrm{~mL}$ of $60 \%$ methanol. The elution of the adsorbed compounds was made using $3 \mathrm{~mL}$ of methanol containing $5 \%$ acetic acid. Before the GCMS analysis all eluted samples were evaporated and reconstituted in $1 \mathrm{~mL}$ of hexane. The quantitative measurements were performed using the integration values of the peak areas in GC chromatogram which was directly proportional to the concentration of the analysed sample. The concentration of the compounds was calculated as $\mathrm{mg} \mathrm{g}^{-1}$ of oil using calibration curves of the pure standards. A massspectrum of each compound was compared to the fragmentation pattern in NIST library and to the spectra available in the literature. In addition, IR was used to confirm the presence of free fatty acids in the eluted samples.

\subsubsection{Method validation}

Method reliability and matrix effects were investigated using the published method in Flakelar et al., (2017) [30]. $1 \mathrm{~mL}$ of heptane was spiked with the mixed standards. $1 \mathrm{~mL}$ of the spiked solution was analysed with GC/MS with the same used conditions of this study and using the calibration curve and the integration of peaks, calculate the percentage of each standard compound in the spiked sample as shown in Table 4. Further matrix effects were examined by comparing the weight of the eluted sample from $20 \%$ sunflower oil in heptane with weight of the eluted sample after subtracting the calculated weight of the natural compounds quantified using GC/MS. The calculations of the concentrations of eluted compounds were performed using the integration of peaks and the calibration curve. 


\section{Results and discussion}

The optimised SPE protocol has been applied to six types of vegetable oils. Almost the same pattern of peaks was observed in the obtained GC/MS chromatogram of all these oils with difference in the intensity of the peaks. To make the comparison easier, the six chromatograms were combined together in one figure (Fig. 1).

Fig. 1:

\subsection{Study of palmitic acid (16:0)}

It was observed that a first compound released from the GC/MS column was recognised palmitic acid (saturated fatty acid, $t_{r}=5.5 \mathrm{~min}$, Fig. 2a). Palmitic acid presents in vegetable oils either in free form or conjugated in ester form $[11,16,21]$. The presence of palmitic acid was confirmed using the comparison of the retention time, the pattern of fragmentations in mass-spectra and IR spectra of free acid and methyl ester forms [31-33]. Both forms, free fatty acids and esters, have been quantified and reported by Eisenmenger and Ghafoor, who estimated content of free fatty acids varying from 0.5 to $22 \%$ and esters from 0.2 to $7.9 \%$, respectively, from the total component of fatty acids in wheat germ oil $[16,33]$.

Fig. 2:

In addition, Eisenmenger and Ghafoor found that free fatty acid content of the vegetable oils does not exceed $60 \mathrm{mg} \mathrm{kg}^{-1}$; however, this number could be amplified to $23.46 \mathrm{mg} \mathrm{g}^{-1}$ in the case of extracting the oil using cold pressing. To reach this level of extraction, all vegetable oils used in this study were either unrefined or obtained by cold pressing; thus, extract relatively measurable levels from the minor components [16]. According to mass-spectra, all the extracted fatty acids in this research are in the free form only.

The experiment presents in that the peak at $5.5 \mathrm{~min}$ is corresponding to palmitic acid according to NIST library mass-spectrum (Fig $2 \mathrm{~b}$ ). It is known that free fatty acids are rarely found when analysed by GC/MS without prior derivatisation, typically their quantification is made using the corresponding methyl ester of these acids [34]. Analysis of the mass-spectra confirmed that the molecular ion of palmitic acid is seen at $m / z 256$. Other fragments at $m / z 115,129,143$, etc. represent fragmentations of the methylene groups of the free fatty acid $\left[\mathrm{HOOC}\left(\mathrm{CH}_{2}\right)_{\mathrm{n}}\right]^{+}$[34]. In Table 1, the comparison between the extracted fatty acids from oil sample and spiked oil shows that spiking the oil sample encouraging the extraction and increasing the harvested fatty acids. The difference between the two concentration (spiked oil and unspiked) confirmed that the difference between them is more than the spiked concentration $\left(0.3 \mathrm{mg} \mathrm{mL}^{-1}\right)$.

It is important to stress that majority of the published data reported the percentage of each fatty acid to the total content of fatty acids after chemical esterification $[8,14,16,24-28]$. Despite some differences in extraction and purification protocols, it was found that the occurrence of the palmitic acid in some vegetable oils in the current study is similar in the order of the quantities to what mentioned by Ramos, who revealed that palm oil is the highest source of saturated free fatty acid (palmitic acid) followed by olive and sunflower oils. This order of quantity of palmitic acid is in accordance with the result in Table 1 (unspiked oil sample) where palm oil has the highest extracted amount of palmitic acid $\left(15.6 \mathrm{mg} \mathrm{g}^{-1}\right)$, then, olive and wheat germ oil (1.19 and $\left.1.14 \mathrm{mg} \mathrm{g}^{-1}\right)$ then sunflower oil $\left(0.94 \mathrm{mg} \mathrm{g}^{-1}\right)$ [3541].

Table 1:

\subsection{Extraction and study of oleic (18:1) and linoleic (18:2) acids}

It was found that the second peak at $t_{r}=7.1$ (Fig. 2a) has contained both mono-unsaturated fatty acid (oleic acid) and di-unsaturated fatty acid (linoleic acid), which were not separated and appeared on the chromatogram as one peak. Therefore, the difference between the oil samples spiked and non-spiked was bigger than in other compounds in this study, because in this case the oil samples were spiked with 
two compounds (oleic and linoleic acids). However, the presence of each of them was examined individually by spiking the oil sample with one of the compounds. The calibration curves were also made for each fatty acid separately. In addition, each peak of oleic and linoleic on GC chromatogram was analysed individually to find out the similarity with the mass-spectrum available in the NIST library as shown in Fig. 2 (c and d). In the mass-spectrum of the oleic acid, the molecular ion was at $m / z 282$ with lower abundance than [M-18] $]^{+}$at $\mathrm{m} / \mathrm{z} 264$ representing the loss of water from the carboxyl group of oleic acid. The most abundant fragments were at the low mass region representing the hydrocarbon ions with general formula $\left[\mathrm{C}_{n} \mathrm{H}_{2 n-1}\right]^{+}$at $m / z 111,125,139$ etc. Similarly, the mass spectrum of linoleic acid was dominated by the hydrocarbon ions of the general formula $\left[\mathrm{C}_{n} \mathrm{H}_{2 n-3}\right]^{+}$at $m / z 109,123$, etc. The molecular ion is at $m / z 280$ with abundance more than [M-18] $]^{+}$at $\mathrm{m} / \mathrm{z} 262[25,42]$.

The same situation in the palmitic acid is noticed in the concentration of oleic and linoleic acids. The difference between the concentration of oleic and linoleic in Table 1 more than the spiked addition. This confirms the importance of the step of spiking oil to encourage the extraction process. It is necessary to point out that almost all published work focused on calculating the percentage of each fatty acid to the total content of fatty acids after transfer all of them (free and conjugated forms) to ester form [14,16,23-27,31-33]. Eisenmenger has quantified the concentration of free fatty acid, which include palmitic, oleic and linoleic acids in the wheat germ oil in the range between 0.2 to $7.9 \mathrm{mg} \mathrm{g}^{-1}$ which correspond to the extracted amount of these acids in the current study (Table 1) [33].

During analysis of olive oil, there were two peaks at 3.34 and 4.5 min with low integrations; therefore, the suggestions of NIST library were not sufficient to identify them. However, it is more likely to be one of the common free saturated fatty acids with molecular weight less than the molecular weight of palmitic acid such as tridecanoic acid (13:0), myristic (14:0) or pentadecanoic acid (15:0) as reported in previous studies $[45,46]$.

\subsection{Study of $\alpha$-tocopherol}

According to the fragmentation pattern in Fig. $2 b, \alpha$-tocopherol was observed as the third common peak, which was coming out of the GC/MS column at $\mathrm{t}_{\mathrm{r}}=14.9 \mathrm{~min}$ (Fig. 2a). It was identified using its molecular ion at $\mathrm{m} / 2430$ and the base fragment of $\left[\mathrm{C}_{10} \mathrm{H}_{13} \mathrm{O}_{2}\right]^{+}$at $\mathrm{m} / 2165$, which represents the dominant ion after opening the ether bond and loss of the side chain of 2,6,10,14-tetramethylpentadec1 -ene [47-51].

Fig. 3:

It was observed that this component showed wide difference between the extracted quantities from the oil sample which was spiked with the standard solution of $\alpha$-tocopherol and extracted without spiking (Table 2). It correlates with the observation made by Feng, who carried out extraction of $\alpha$ tocopherol using a molecularly imprinted polymer synthesised using MAA as a functional monomer and EGDMA as a cross-linker [28,51]. The author reported that the increase of the initial concentration of $\alpha-$ tocopherol leads to increase the adsorption capacity of the molecularly imprinted polymer. Therefore, the quantities of eluted $\alpha$-tocopherol from spiked oil samples are more comparable (Table 2 ) to the extracted from the unsaponifiable matter of the vegetable oils were reported in the literature.

Table 2:

Although the amount of $\alpha$-tocopherol extracted from oils without spiking was very small comparing to the extracted amount from the spiked samples, the ratios between the extracted amounts from the spiked oil samples were in agreement with some results published by some studies as shown in Table (2). The highest extracted amount was obtained from the wheat germ oil (natural and spiked oil samples) (0.298 and $1.357 \mathrm{mg} \mathrm{g}^{-1}$ ) and the lowest amount was extracted from sesame oil (in natural oil sample was not detected and in spiked oil sample $0.867 \mathrm{mg} \mathrm{g}^{-1}$ ).

\subsection{Study of phytosterols}

The next group of compounds are members of the phytosterols family, which could be present in free or esterified forms $[17,19,51]$. Since the current purification method was applied to oil solution without 
any pre-treatment, therefore it is possible to conclude that extracted phytosterols were mainly present in their free forms as shown in Fig. 4a.

\subsubsection{Campesterol}

Based on the mass spectra fragments (Fig. 4b), the first free phytosterol peak coming out of the GC/MS column at $t_{r}=15.7$ min was identified as campesterol (Fig. 4a). On the mass-spectrum (Fig. 4b), the molecular ion $[\mathrm{M}]^{+}$of campesterol at $\mathrm{m} / \mathrm{z} 400$ and the typical fragments of campesterol were observed at $m / z 385$ for the ion $\left[\mathrm{M}-\mathrm{CH}_{3}\right]^{+}, m / z 382$ for the ion $\left[\mathrm{M}-\mathrm{H}_{2} \mathrm{O}\right]^{+}$and $m / z 367$ for the fragment $\left[\mathrm{M}-\mathrm{CH}_{3}-\right.$ $\left.\mathrm{H}_{2} \mathrm{O}\right]^{+}[59]$. As shown in Table 3, the quantitative data obtained are comparable with the results of Eisenmenger for wheat germ, sunflower, sesame and olive oils and Purcaro for palm oil [17,23,51].

The quantitative studies report the occurrence of the phytosterols, particularly, campesterol, in the vegetable oils at the level close to what obtained in this study (Table 3). Although the campesterol generally appeared as the most minor member of phytosterols family, it was found in the highest concentration in wheat germ oil and the smallest concentration in olive oil.

\subsubsection{Stigmasterol}

The MS fragmentation pattern (Fig. 4c) of the peak at $t_{r}=15.9 \mathrm{~min}$ in the chromatogram (Fig. 4a) was identified as stigmasterol. The molecular ion $[\mathrm{M}]^{+}$of stigmasterol appeared at $\mathrm{m} / z 412$, other distinctive fragments included $m / z 397$ for $\left[\mathrm{M}-\mathrm{CH}_{3}\right]^{+}, m / z 394$ for $\left[\mathrm{M}-\mathrm{H}_{2} \mathrm{O}\right]^{+}, m / z 369$ for $\left[\mathrm{M}-\mathrm{C}_{3} \mathrm{H}_{5}\right]^{+}, m / z 351$ for $[\mathrm{M}-$ $\left.\mathrm{C}_{3} \mathrm{H}_{5}-\mathrm{H}_{2} \mathrm{O}\right]^{+}$and the ion at $m / z 314$ for $\left[\mathrm{M}-\mathrm{C}_{7} \mathrm{H}_{14}\right]^{+}[59]$.

It was observed that the ratio between the main three different sterols in wheat germ, sesame, sunflower and olive oil as reported in Table 3 were in accordance with the values mentioned in some published studies.

Fig. 4:

\subsection{3. $\beta$-sitosterol}

$\beta$-sitosterol is the major sterol in the vegetable oils. In the current study, the $\beta$-sitosterol has been extracted at the highest amount comparing to the other sterols in all oils which in accordance with the previously published quantitative data $[17,19,23,24,51]$. According to the mass spectrum fractions in Fig. $4 d$, the peak on the chromatograms of the eluted samples with $t_{r}=16.2$ min was identified as $\beta$ sitosterol. The distinctive fragments included the molecular ion [M] ${ }^{+} \mathrm{m} / z 414, \mathrm{~m} / z 399$ corresponding $\left[\mathrm{M}-\mathrm{CH}_{3}\right]^{+}, m / z 396$ for $\left[\mathrm{M}-\mathrm{H}_{2} \mathrm{O}\right]^{+}, m / z 381$ for $\left[\mathrm{M}-\mathrm{CH}_{3}-\mathrm{H}_{2} \mathrm{O}\right]^{+}, m / z 329$ for $\left[\mathrm{M}-\mathrm{C}_{6} \mathrm{H}_{13}\right]^{+}$and $m / z 303$ for $[\mathrm{M}-$ $\left.\mathrm{C}_{7} \mathrm{H}_{11} \mathrm{O}\right]^{+}[59]$.

In order to measure the total amount of the phytosterols, they are commonly subjected to the transesterification reaction where converts them from free to ester form, which is used for analysis $[50,52]$. The presented here, the RDP-based SPE protocol allows selectively adsorbing and eluting these compounds in their free form.

\section{Table 3:}

The comparison between the current measurements and published data confirmed that there was a correlation between the current quantitative measurements extracted from the oils by the optimised protocol and the data published in different studies as summarised in Table 3.

\subsection{Extraction of other minor components}

There was a noticeable peak at $t_{r}=15.3 \mathrm{~min}$ on the chromatogram of the sample purified from sesame oil (Fig. 1), that showed a component that appeared at very high concentration. The comparison of the fragments pattern of mass spectrum (Fig. 5) with NIST library suggested that this compound could be identified as sesamin. The spectrum contained the molecular ion [M] ${ }^{+} \mathrm{m} / z 354$, the base peak $m / z 149$ that corresponded to the [1,3-dioxymethylenephenyl-CO $]^{+}$fragment, $m / z 121$ [1,3-dioxymethylphenyl] ${ }^{+}$ fragment, $m / z 135$ ion [1,3-dioxymethylenephenyl- $\mathrm{CH} 2]^{+}, m / z \quad 161$ ion [1,3-dioxymethylenephenyl$\left.\mathrm{CHCHCH}_{2}\right]^{+}, \mathrm{m} / \mathrm{z} 203$ ion [M-(1,3-dioxymethylenephenyl-CHO-H)] $]^{+}$, and $\mathrm{m} / z 336\left[\mathrm{M}-\mathrm{H}_{2} \mathrm{O}\right]^{+}[3,46,53]$. 
Fig. 5:

The presence of sesamin was confirmed using sesame oil spiked with $0.3 \mathrm{mg}$ of sesamin and the retention time was compared by injection of the standard sesamin solution, which appeared identical. The standard solution of sesamin in hexane was used to produce a calibration curve. It was calculated that the eluted amount of sesamin from sesame oil was estimated as $3.12 \pm 0.88 \mathrm{mg} \mathrm{g}^{-1}$ and from the spiked oil $3.57 \pm 0.46 \mathrm{mg} \mathrm{g}^{-1}$. These measurements were in accordance with amount of sesamin extracted from the unrefined oil by Jin $\left(4.30 \mathrm{mg} \mathrm{g}^{-1}\right)$, Wu (3.36 to $4.9 \mathrm{mg} \mathrm{g}^{-1}$ ), Moazzami (4.44 to $16.01 \mathrm{mg} \mathrm{g}^{-1}$ ) and from the refined oil (1.18 to $4.01 \mathrm{mg} \mathrm{g}^{-1}$ ) by Dachtler $\left(4.74 \mathrm{mg} \mathrm{g}^{-1}\right)$ [61-66].

\subsection{Method validation}

The proposed method to measure the determine matrix effects was performed by examining the percentage of the spiking standards (palmitic, oleic, linoleic acids, $\alpha$-tocopherol, campesterol, stigmasterol and $\beta$-sitosterol. Satisfactory recoveries were determined for these solutions, with values ranging from $94-99 \%$ as shown in Table 4 . The purification percentage was evaluated by comparing the dry weight of the $20 \%$ oil sample before SPE $(200 \pm 5 \mathrm{mg})$ and a dry weight of the eluted sample after SPE $(21.45 \pm 4.8 \mathrm{mg})$. Considering that $18.52 \pm 5.2 \mathrm{mg}$ of the eluted sample constitutes a weight of the natural compounds which were quantified using GC/MS, only $2.93 \mathrm{mg}$ of the matrix is remained which is equivalent of $1.4 \%$. Therefore, a very high level of purification of $98.6 \%$ was achieved.

Blank samples were run to check the possibility of memory effect from the analysis of high concentration in the calibration curve. No signal has been given that interfered with the peaks, confirming no memory effect in the chromatographic run.

\section{Table 4:}

Analysis of minor fat-soluble compounds in vegetable oils can be challenging due to the interference from the oily matrix $[18,67]$. The challenging is presenting in the requirement of complex pre-treatment of the sample to make the hydrophobic sample suitable for the reverse phase (RP) HPLC. Therefore, there is a demand to develop new extraction methods to overcome these challenges and optimise simple and efficient methods. Several published studies suggested simultaneous separation and quantification protocols of some minor components from vegetable oils [68-71]. Almost of these studies depended on optimised chromatographic separation with appropriate detecting techniques to extract tocopherols and carotenoids from different types of vegetable oils. However, all these methods required sample preparation and did not include the phytosterols.

Further analysis methods have emerged to include the separation of phytosterols beside tocopherols and other minor components such as squalene or carotenoids [18,72-75]. However, the pre-treatment processes of oil samples to separate such compounds needed more complex processes such as methylation or saponification, purification and derivatisation which led to loss of phytosterols.

The advantages of the developed RDP and optimised SPE protocol in the current research over the traditional methods of extraction included the separation of the minor compounds with 5 times dilution of the vegetable. This dilution rate is twice improved by comparison with the 10-fold dilution applied in the industrial protocol, leading to decrease the organic solvents waste and saving in the resources and time. It was also exhibited that the combination of the optimised SPE method and synthesised RDP enabled a quantitative extraction of minor compounds from sex types of vegetable oils to be performed without any additional pre-treatment. It is important to underline that the optimised protocols and suggested strategy could be used as proposals for the development of extraction procedures for different groups of compounds from other natural oil-containing biomasses.

\section{Conclusions}

A new method has been validated for the extraction of seven minor compounds from the six vegetable oils using heptane without any pre-treatment for the oil sample. It was shown that it was possible to harvest those physiologically-active components in their free forms as it was confirmed using GC/MS. The extracted compounds included free fatty acids, $\alpha$-tocopherol and three free phytosterols from six 
types of vegetable oils, despite the variability of the content of the minor components in each of these oils. Moreover, the quantitative results of this study were comparable with published data that used various methods and techniques to extract these minor components from the vegetable oils. The benefit of this protocol is a reduction the use of the organic solvents and save the cost and time compared to the previously published methods because there is no need for any pre-treatment or derivatisation of the free fatty acids, $\alpha$-tocopherol or free phytosterols before the extraction. The proposed method has achieved the separation with $98.6 \%$ level of purification based on the study of matrix effect.

To conclude, the data presented here confirm that developed protocol provides a quantitative extraction of the six minor compounds which were purified using reduced volumes of organic solvents and without any pre-treatment or derivatization. Finally, the developed protocol could serve as a blueprint for design and development of the bespoke materials and SPE protocols that will contribute to more sustainable society.

\section{Acknowledgements}

The authors are thankful for the financial support provided by the King Abdul Aziz University in Kingdom of Saudi Arabia under the form of PhD grant K\33/10716. A great acknowledge to Mick Lee for his technical support with this research.

\section{References:}

(1) A. Demirbas, Political, Economic and Environmental Impacts of Biofuels: A Review, Appl. Energy 86 (2009) S108-S117.

(2) M. Lechner, B. Reiter, E. Lorbeer, Determination of Tocopherols and Sterols in Vegetable Oils by Solid-Phase Extraction and Subsequent Capillary Gas Chromatographic Analysis, J. Chromatogr. A, 857 (1999) 231-238.

(3) E. Ballesteros, M. Gallego, M. Valcárcel, Gas Chromatographic Determination of Cholesterol and Tocopherols in Edible Oils and Fats with Automatic Removal of Interfering Triglycerides, J. Chromatogr. A, 719 (1996) 221-227.

(4) A. Moazzami, A. Kamal-Eldin, Sesame Seed Oil, in: R. Moreau, A. Kamal-Eldin (Eds.) Gourmet and Health-Promoting Specialty Oils, AOCS Press., Urbana, 2009, pp. 267-282.

(5) E.F. Aransiola, T.V. Ojumu, O.O. Oyekola, T.F. Madzimbamuto, D. Ikhu-Omoregbe, Review of Current Technology for Biodiesel Production: State of the Art, Biomass Bioenergy, 61 (2014) 276-297.

(6) B. Freedman, E.H. Pryde, T.L. Mounts, Variables Affecting the Yields of Fatty Esters from Transesterified Vegetable Oils, J. Am. Oil Chem. Soc., 61 (1984) 1638-1643.

(7) J. Van Gerpen, Biodiesel Processing and Production, Fuel Process. Technol., 86 (2005) 10971107.

(8) A. Mancini, E. Imperlini, E. Nigro, C. Montagnese, A. Daniele, S. Orrù, P. Buono, Biological and Nutritional Properties of Palm Oil and Palmitic Acid: Effects on Health, Molecules, 20 (2015) 17339-17361.

(9) P.M. Kris-Etherton, T.A. Pearson, Y. Wan, R.L. Hargrove, K. Moriarty, V. Fishell, T. Etherton, High-Monounsaturated Fatty Acid Diets Lower Both Plasma Cholesterol and Triacylglycerol Concentrations, Experimental Design, Am. J. Clin. Nutr., 70 (1999) 1009-1015.

(10) J. Yi, W. Zhu, H. Ma, Y. Wang, Optimization on Ultrasonic-Assisted Extraction Technology of Oil from Paeonia Suffruticosa Andr. Seeds with Response Surface Analysis. Nongye Jixie Xuebao, 40 (2009) 103-110.

(11) P. Pająk, R. Socha, D. Gałkowska, J. Rożnowski, T. Fortuna, Phenolic Profile and Antioxidant Activity in Selected Seeds and Sprouts, Food Chem., 143 (2014) 300-306.

(12) Z. Luo, B.S. Murray, A.L. Ross, M.J.W. Povey, M.R.A. Morgan, A.J. Day, Effects of PH on the Ability of Flavonoids to Act as Pickering Emulsion Stabilizers, Colloids Surf. B Biointerfaces 92 (2012) 84-90. 
(13) F. Puoci, G. Cirillo, M. Curcio, F. lemma, U. Spizzirri, Molecular Imprinted SPE of Selective HPLC Determination of A-Tocopherol in Bay Leave. Anal. Chim. Acta., 593 (2007) 164-170.

(14) A. Azzi, A. Stocker, Vitamin E: Non-Antioxidant Roles, Prog. Lipid Res., 39 (2000) 321-255.

(15) S. Lemaire-Ewing, C. Desrumaux, D. Néel, L. Lagrost, Vitamin E Transport, Membrane Incorporation and Cell Metabolism: Is Alpha-Tocopherol in Lipid Rafts an Oar in the Lifeboat? Mol. Nutr. Food Res. 54 (2010) 631-640.

(16) K. Ghafoor, M.M. Ozcan, F. Al-Juhaimi, E.E. Babiker, Z.I. Sarker, I.A.M. Ahmed, M.A. Ahmed, Nutritional Composition, Extraction, and Utilization of Wheat Germ Oil: A Review, Eur. J. Lipid Sci. Technol., 118 (2017) 1-9.

(17) H. Schwartz, V. Ollilainen, V. Piironen, A.M. Lampi, Tocopherol, Tocotrienol and Plant Sterol Contents of Vegetable Oils and Industrial Fats, J. Food Compos. Anal., 21 (2008) 152-161.

(18) S.L. Abidi, S. Thiam, I.M. Warner, Elution Behaviour of Unsaponifiable Lipids with Various Capillary Electro Chromatographic Stationary Phases, J. Chromatogr. A, 949 (2002) 195-207.

(19) B. Reiter, M. Lechner, E. Lorbeer, R. Aichholz, Isolation and Characterization of Wax Esters in Fennel and Caraway Seed Oils by SPE-GC, J. High Resolut. Chromatogr., 22 (1999) 514-520.

(20) P.M. Bramley, I. Elmadfa, A. Kafatos, F.J. Kelly, Y. Manios, H.E. Roxborough, W. Schuch, P.J.a Sheehy, K.H. Wagner, Vitamin E, J. Sci. Food Agric., 80 (1999) 913-938.

(21) M. Galea, C. Horga, Separation and Determination of Tocopherols in Vegetable Oil by SPE, Cent. Eur. J. Chem., 8 (2010) 110- 116.

(22) F. Qiao, H. Sun, H. Yan, K.H. Row, Molecularly Imprinted Polymers for Solid Phase Extraction. Chromatographia 64 (2006) 625-634.

(23) E. Gimeno, A.I. Castellote, R.M. Lamuela-Raventos, M.C. De La Torre, M.C. Loppez-Sabater, Rapid Determination of Vitamin E in Vegetable Oils by Reversed-Phase High-Performance Liquid Chromatography, J. Chromatogr. A, 881 (2000) 251-254.

(24) E. Turrell, L. Stobo, J.P. Lacaze, S. Piletsky, E. Piletska, Optimization of Hydrophilic Interaction Liquid Chromatography/Mass Spectrometry and Development of Solid-Phase Extraction for the Determination of Paralytic Shellfish Poisoning Toxins, J. AOAC Int., 91 (2008) 1372-1386.

(25) A. Guerreiro, A. Soares, E. Piletska, B. Mattiasson, S. Piletsky, Preliminary Evaluation of New Polymer Matrix for Solid-Phase Extraction of Nonylphenol from Water Samples, Anal. Chim. Acta 612 (2008) 99-104.

(26) I. Bakas, N. Ben Oujji, E. Moczko, G. Istamboulie, S. Piletsky, E. Piletska, I. Ait-Ichou, E. Ait-Addi, T. Noguer, R. Rouillon, Molecular Imprinting Solid Phase Extraction for Selective Detection of Methidathion in Olive Oil, Anal. Chim. Acta., 734 (2012) 99-105.

(27) I. Bakas, N.B. Oujji, E. Moczko, G. Istamboulie, S. Piletsky, E. Piletska, E. Ait-Addi, I. Ait-Ichou, T. Noguer, R. Rouillon, Computational and Experimental Investigation of Molecular Imprinted Polymers for Selective Extraction of Dimethoate and Its Metabolite Omethoate from Olive Oil, J. Chromatogr. A, 1274 (2013) 13-18.

(28) S. Feng, F. Gao, Z. Chen, E. Grant, D.D. Kitts, S. Wang, X. Lu, Determination of $\alpha$-Tocopherol in Vegetable Oils Using a Molecularly Imprinted Polymers-Surface-Enhanced Raman Spectroscopic Biosensor, J. Agric. Food Chem., 61 (2013) 10467-75.

(29) E.M. Alghamdi, M.J. Whitcombe, S.A. Piletsky, E.V. Piletska, Solid Phase Extraction of $\alpha$ Tocopherol and Other Physiologically Active Components from Sunflower Oil Using Rationally Designed Polymers. Anal. Methods, 10 (2018) 314-321.

(30) C.L. Flakelar, P.D. Prenzler, D.J. Luckett, J.A. Howitt, G. Doran, A Rapid Method for the Simultaneous Quantification of the Major Tocopherols, Carotenoids, Free and Esterified Sterols in Canola (Brassica Napus) Oil Using Normal Phase Liquid Chromatography, Food Chem., 214 (2017) 147-155. 
(31) R.A. Moreau, B.D. Whitaker, K.B. Hicks, Phytosterols, Phytostanols, and Their Conjugates in Foods: Structural Diversity, Quantitative Analysis, and Health-Promoting Uses, Prog. Lipid Res. 41 (2002) 457-500.

(32) A. Cert, W. Moreda, M. Pérez-Camino, Chromatographic Analysis of Minor Constituents in Vegetable Oils, J. Chromatogr. A, 881 (2000) 131-148.

(33) M. Eisenmenger, N.T. Dunford, Bioactive Components of Commercial and Supercritical Carbon Dioxide Processed Wheat Germ Oil, J. Am. Oil Chem. Soc., 85 (2008) 55-61.

(34) W.W. Christie, The Lipid Web http://www.lipidhome.co.uk/ms/others/ffa-tms/index.htm (accessed Oct 1, 2017).

(35) K. Nill, Soy Beans: Properties and Analysis, in: Catallcro B., Finglas P., Toldra F. (Eds.), Encyclopedia of Food and Health, Elsevier Ltd., Oxford, 2016, pp. 54-55.

(36) F. Longobardi, A. Ventrella, G. Casiello, D. Sacco, L. Catucci, A. Agostiano, M.G. Kontominas, Instrumental and Multivariate Statistical Analyses for the Characterisation of the Geographical Origin of Apulian Virgin Olive Oils, Food Chem., 133 (2012) 579-584.

(37) M. Koushki, M. Nahidi, F. Cheraghali, Physico-Chemical Properties, Fatty Acid Profile and Nutrition in Palm Oil, J. Paramed. Sci., 6 (2015) 117-134.

(38) B. Xu, J. Han, S. Zhou, Q. Wu, F. Ding, Quality Characteristics of Wheat Germ Oil Obtained by Innovative Subcritical Butane Experimental Equipment, J. Food Process Eng., 39 (2016) 79-87.

(39) A. Kan, Chemical and Elemental Characterization of Wheat Germ Oil Cultivated in Turkey, Afr. J. Agric. Reseearch, 7 (2012) 4979-4982.

(40) G.S. Kumar, A.G.G. Krishna, Studies on the Nutraceuticals Composition of Wheat Derived Oils Wheat Bran Oil and Wheat Germ Oil, J. Food Sci. Technol., 52 (2013) 1145-1151.

(41) M.J. Ramos, C.M. Fernandez, A. Casas, L. Rodriguez, A. Perez, Influence of Fatty Acid Composition of Raw Materials on Biodiesel Properties, Bioresour. Technol., 100 (2009) 261268.

(42) C.M. Guttman, Mass Spectrometry Principles and Applications, third ed., John Wiley \& Sons Ltd, West Sussex, 2001.

(43) D.M. Hegde, Sesame, in Peter K.V. (Ed.), Handbook of Herbs and Spices, Woodhead Publishing Limited, Cambridge, 2012, pp. 267-282.

(44) S. Gharby, H. Harhar, Z. Bouzoubaa, A. Asdadi, A. El Yadini, Z. Charrouf, Steam Explosion Technology Based for Oil Extraction from Sesame (Sesamum Indicum L.) Seed, Food Chem. 7 (2014) 194-197.

(45) M. Monfreda, L. Gobbi, A. Grippa, Blends of Olive Oil and Sunflower Oil: Characterisation and Olive Oil Quantification Using Fatty Acid Composition and Chemometric Tools, Food Chem., 134 (2012) 2283-2290.

(46) S.M. Wabaidur, A. AlAmmari, A. Aqel, S.A. AL-Tamrah, Z.A. Alothman, A.Y. Ahmed, Determination of Free Fatty Acids in Olive Oils by UPHLC-MS, J. Chromatogr. B, 1031 (2016) 09115.

(47) E. Bartosińska, M. Buszewska-Forajta, D. Siluk, GC-MS and LC-MS Approaches for Determination of Tocopherols and Tocotrienols in Biological and Food Matrices, J. Pharm. Biomed. Anal., 127 (2016) 156-169.

(48) A. Fiorentino, C. Mastellone, B. D’Abrosca, S. Pacifico, M. Scognamiglio, G. Cefarelli, R. Caputo, P. Monaco, a-Tocomonoenol: A New Vitamin E from Kiwi (Actinidia Chinensis) Fruits, Food Chem. 115 (2009) 187-192.

(49) P.P. Nair, Z. Luna, Identification of $\alpha$-Tocopherol from Tissues by Combined Gas-Liquid Chromatography, Mass Spectrometry and Infrared Spectroscopy, Arch. Biochem. Biophys., 127 (1968) 413-418. 
(50) K. Nagy, M.C. Courtet-Compondu, B. Holst, M. Kussmann, Comprehensive Analysis of Vitamin E Constituents in Human Plasma by Liquid Chromatography-Mass Spectrometry, Anal. Chem. 79 (2007) 7087-7096.

(51) L. Zou, C.C. Akoh, Identification of Tocopherols, Tocotrienols, and Their Fatty Acid Esters in Residues and Distillates of Structured Lipids Purified by Short-Path Distillation, J. Agric. Food Chem., 61 (2013) 238-246.

(52) M. Gonzalez, E. Ballesteros, M. Gallego, M. Valcarcel, Continuous-Flow Determination of Natural and Synthetic Antioxidants in Foods by Gas Chromatography, Anal. Chim. Acta., 359 (1998) 47-55.

(53) J.A. Cayuela, J.F. García, Sorting Olive Oil Based on Alpha-Tocopherol and Total Tocopherol Content Using Near-Infra-Red Spectroscopy (NIRS) Analysis, J. Food Eng., 202 (2017) 79-88.

(54) D. Grigoriadou, A. Androulaki, E. Psomiadou, M.Z. Tsimidou, Solid Phase Extraction in the Analysis of Squalene and Tocopherols in Olive Oil, Food Chem., 105 (2007) 675-680.

(55) J. Lee, E. Choe, Extraction of Lignan Compounds from Roasted Sesame Oil and Their Effects on the Autoxidation of Methyl Linoleate, J. Food Sci., 71 (2006) 430-436.

(56) A.J. Dijkstra, Soybean Oil. in: B. Catallcro, P. Finglas, F. Toldra (Eds.), Encyclopedia of Food and Health, Elsevier Ltd., Oxford, 2016, pp.58-63.

(57) V. Gibon, P. Dijckmans, W.D.E. Greyt, Future Prospects for Palm Oil Refining and Modifications, Innov. Technol., 16 (2009) 193-200.

(58) V.M. Koistinen, K. Hanhineva, Mass Spectrometry-Based Analysis of Whole-Grain Phytochemicals, Crit. Rev. Food Sci. Nutr., 57 (2017) 1688-1709.

(59) P. Suttiarporn, W. Chumpolsri, S. Mahatheeranont, S. Luangkamin, S. Teepsawang, V. Leardkamolkarn, Structures of Phytosterols and Triterpenoids with Potential Anti-Cancer Activity in Bran of Black Non-Glutinous Rice. Nutrients, 7 (2015) 1672-1687.

(60) G. Purcaro, L. Barp, M. Beccaria, L.S. Conte, Characterisation of Minor Components in Vegetable Oil by Comprehensive Gas Chromatography with Dual Detection, Food Chem., 212 (2016) 730-738.

(61) P.C. Dutta, Phytosterols as Functional Food Components and Nutraceuticals, Marcel Dekker INC., New York, 2004.

(62) G. Yan, Q. Li, T. Huarong, T. Ge, Electrospray Ionization Ion-Trap Time-of-Flight Tandem Mass Spectrometry of Two Furofurans: Sesamin and Gmelinol, Rapid Commun. Mass Spectrom., 21 (2007) 3613-3620.

(63) M. Dachtler, F.H. Van De Put, F.V. Stijn, C.M. Beindorff, J. Fritsche, On-Line LC-NMR-MS Characterization of Sesame Oil Extracts and Assessment of Their Antioxidant Activity, Eur. J. Lipid Sci. Technol., 105 (2003) 488-496.

(64) J.H. Kim, W.D. Seo, S.K. Lee, Y.B. Lee, C.H. Park, H.W. Ryu, J.H. Lee, Comparative Assessment of Compositional Components, Antioxidant Effects, and Lignan Extractions from Korean White and Black Sesame (Sesamum Indicum L.) Seeds for Different Crop Years, J. Funct. Foods, 7 (2014) 495-505.

(65) W.H. Wu, The Contents of Lignans in Commercial Sesame Oils of Taiwan and Their Changes during Heating, Food Chem., 104 (2007) 341-344.

(66) A.A. Moazzami, S.L. Haese, A. Kamal-Eldin, Lignan Contents in Sesame Seeds and Products. Eur. J. Lipid Sci. Technol., 109 (2007) 1022-1027.

(67) A. Carrasco-Pancorbo, N. Navas-Iglesias, L. Cuadros-Rodríguez, From Lipid Analysis towards Lipidomics, a New Challenge for the Analytical Chemistry of the 21st Century. Part I: Modern Lipid Analysis, Trends Analyt. Chem., 28 (2009) 263-278.

(68) E. Psomiadou, M. Tsimidou, Simultaneous HPLC Determination of Tocopherols, Carotenoids, and Chlorophylls for Monitoring Their Effect on Virgin Olive Oil Oxidation, J. Agric. Food Chem., 
46 (1998) 5132-5138.

(69) I. Valdivielso, M.Á. Bustamante, J.C. Ruiz de Gordoa, A.I. Nájera, M. de Renobales, L.J.R. Barron, Simultaneous Analysis of Carotenoids and Tocopherols in Botanical Species Using One Step Solid-Liquid Extraction Followed by High Performance Liquid Chromatography, Food Chem., 173 (2015) 709-717.

(70) C.L. Flakelar, D.J. Luckett, J.A. Howitt, G. Doran, P.D. Prenzler, Canola (Brassica Napus) Oil from Australian Cultivars Shows Promising Levels of Tocopherols and Carotenoids, along with Good Oxidative Stability, J. Food Compos. Anal., 42 (2015) 179-186.

(71) M. Fromm, S. Bayha, D.R. Kammerer, R. Carle, Identification and Quantitation of Carotenoids and Tocopherols in Seed Oils Recovered from Different Rosaceae Species, J. Agric. Food Chem., 60 (2012) 10733-10742.

(72) I.B. Abdallah, N. Tlili, E. Martinez-Force, A.G.P. Rubio, M.C. Perez-Camino, A. Albouchi, S. Boukhchina, Content of Carotenoids, Tocopherols, Sterols, Triterpenic and Aliphatic Alcohols, and Volatile Compounds in Six Walnuts (Juglans Regia L.) Varieties, Food Chem., 173 (2015) 972-978.

(73) T. Verleyen, R. Verhe, K. Dewettinck, A. Huyghebaert, W. Greyt, M. Forcades, Analysis of Free and Esterified Sterols in Vegetable Oils, J. Am. Oil Chem. Soc., 79 (2002) 117-122.

(74) M. Yang, M. Zheng, Q. Zhou, F. Huang, C. Liu, S. Wang, Minor Components and Oxidative Stability of Cold-Pressed Oil from Rapeseed Cultivars in China, J. Food Compos. Anal., 29 (2013) 1-9.

(75) C. Li, Y. Yao, G. Zhao, Y. Chen, H. Liu, C. liu, Z. Shi, Y. Chen, S. Wang, Comparison and Analysis of Fatty Acids, Sterols, and Tocopherols in Eight Vegetable Oils, J. Agric. Food Chem., 59 (2011) 12493-12498. 


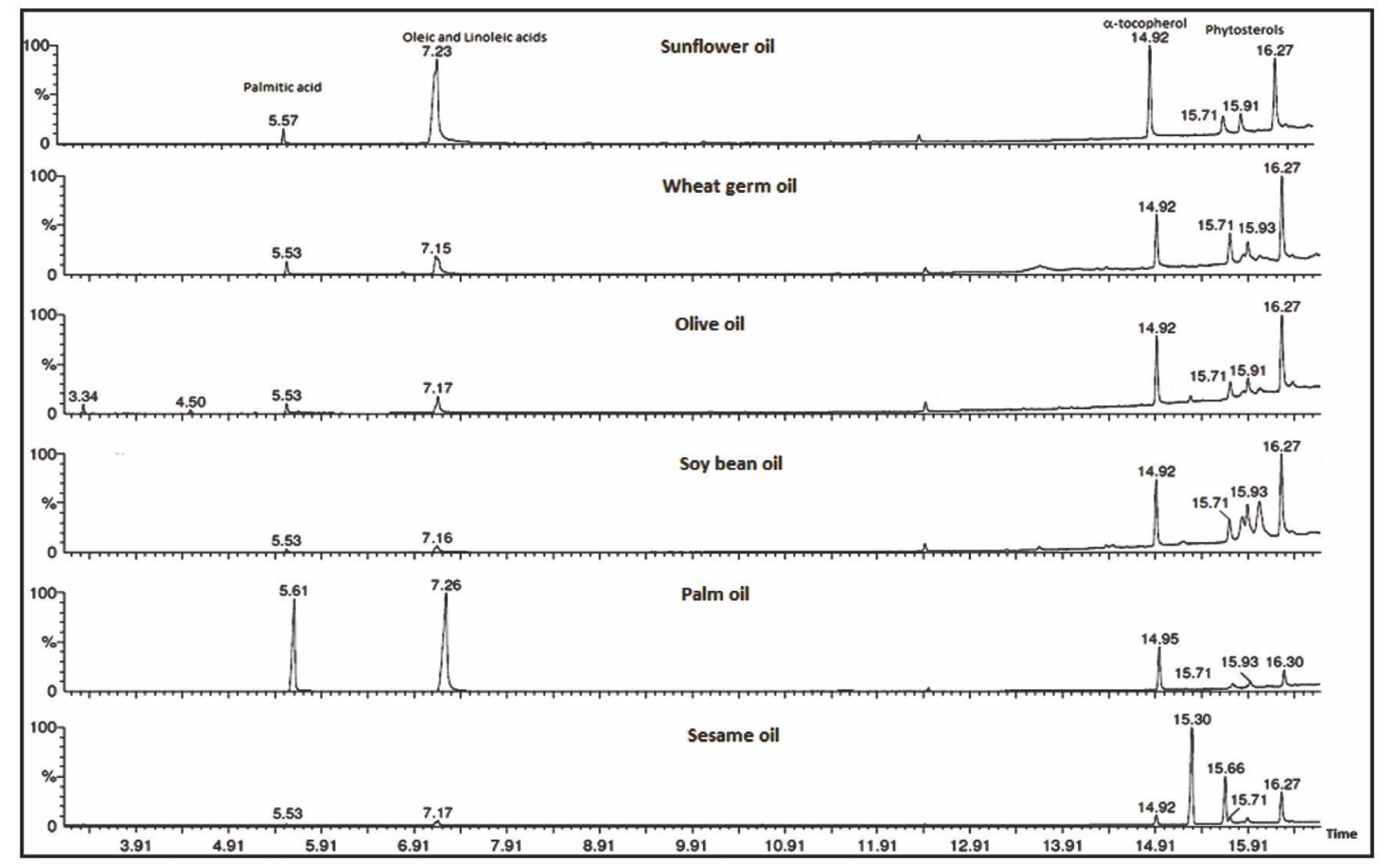

Fig 1: GC chromatograms of the eluted samples from six different vegetable oils spiked with seven standards (this experiment was repeated three times). 


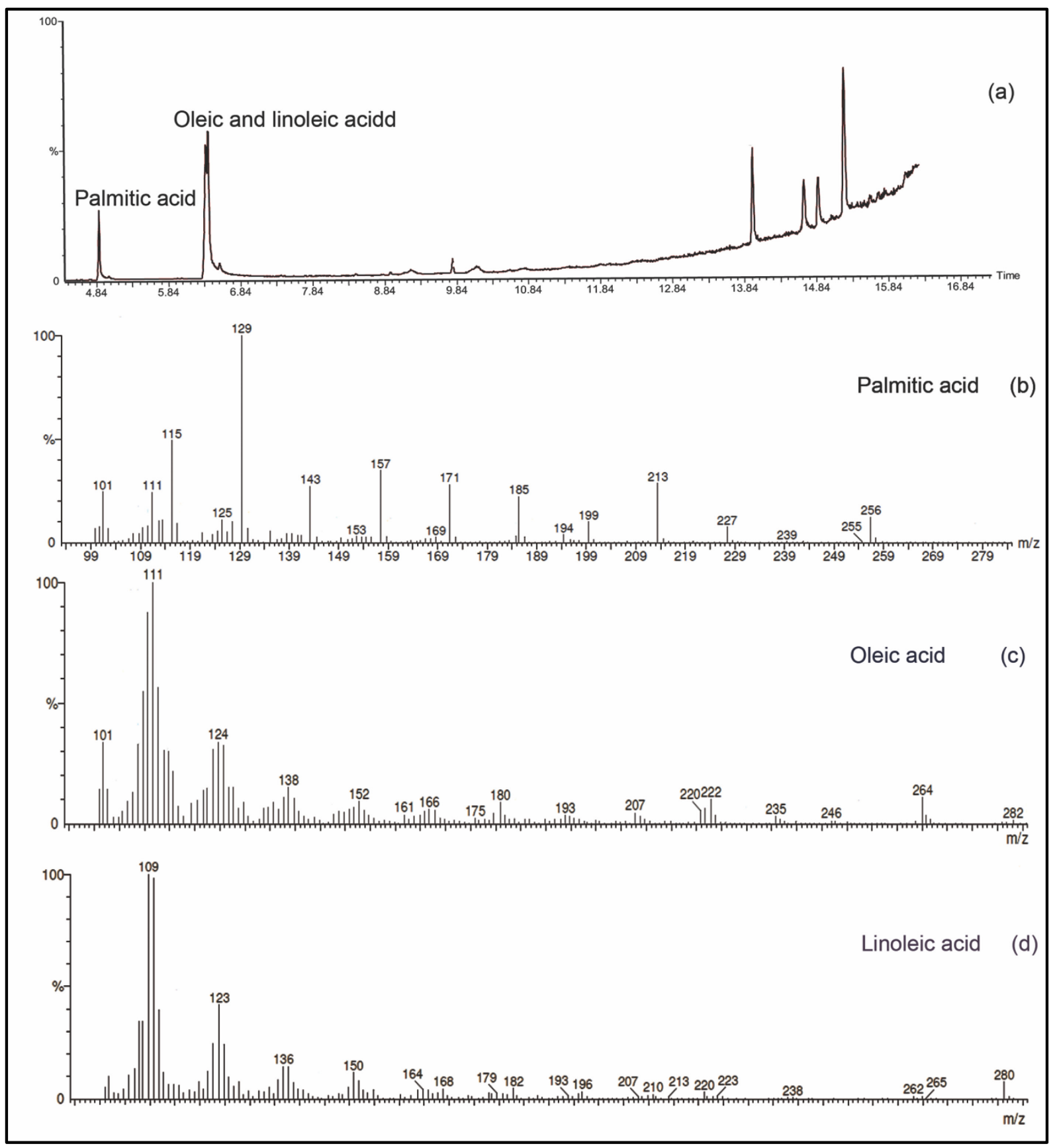

Fig 2: Chromatogram of the eluted sample from sunflower oil labelled the peaks corresponding to the free fatty acids only (a). Mass spectra of fatty acids: palmitic (b), oleic (c) and linoleic acids(d). 
Table 1: Quantities of eluted fatty acids from $20 \%$ of different vegetable oils (average of triplicate \pm standard deviation).

\begin{tabular}{|c|l|c|c|}
\hline Vegetable oil & Fatty acid & $\begin{array}{c}\text { Quantity in spiked } \\
\text { oil solution }\left(\mathbf{m g ~ g}^{-1}\right)\end{array}$ & $\begin{array}{c}\text { Quantity in unspiked } \\
\text { oil solution }\left(\mathbf{m g ~ g}^{-1}\right)\end{array}$ \\
\hline \multirow{2}{*}{ Sunflower } & Palmitic & $1.82 \pm 0.8$ & $0.942 \pm 0.09$ \\
\cline { 2 - 4 } & Oleic and linoleic & $28.411 \pm 6.7$ & $16.425 \pm 4.8$ \\
\hline \multirow{2}{*}{ Wheat germ } & Palmitic & $1.73 \pm 0.09$ & $1.14 \pm 0.51$ \\
\cline { 2 - 4 } & Oleic and linoleic & $10.41 \pm 4.3$ & $7.181 \pm 1.31$ \\
\hline \multirow{2}{*}{ Olive } & Palmitic & $2.16 \pm 0.12$ & $1.19 \pm 0.13$ \\
\cline { 2 - 4 } & Oleic and linoleic & $3.823 \pm 1.19$ & $1.325 \pm 0.87$ \\
\hline \multirow{2}{*}{ Poybean } & Palmitic & $1.22 \pm 0.13$ & $0.004 \pm 0.002$ \\
\cline { 2 - 4 } & Oleic and linoleic & $2.719 \pm 0.77$ & $0.088 \pm 0.012$ \\
\hline \multirow{2}{*}{ Sesame } & Palmitic & $16.28 \pm 1.43$ & $15.6 \pm 1.87$ \\
\cline { 2 - 4 } & Oleic and linoleic & $38.914 \pm 7.5$ & $34.496 \pm 8.4$ \\
\cline { 2 - 4 } & Palmitic & $0.62 \pm 0.06$ & $0.366 \pm 0.14$ \\
\cline { 2 - 4 } & Oleic and linoleic & $6.246 \pm 2.19$ & $2.407 \pm 0.12$ \\
\hline
\end{tabular}




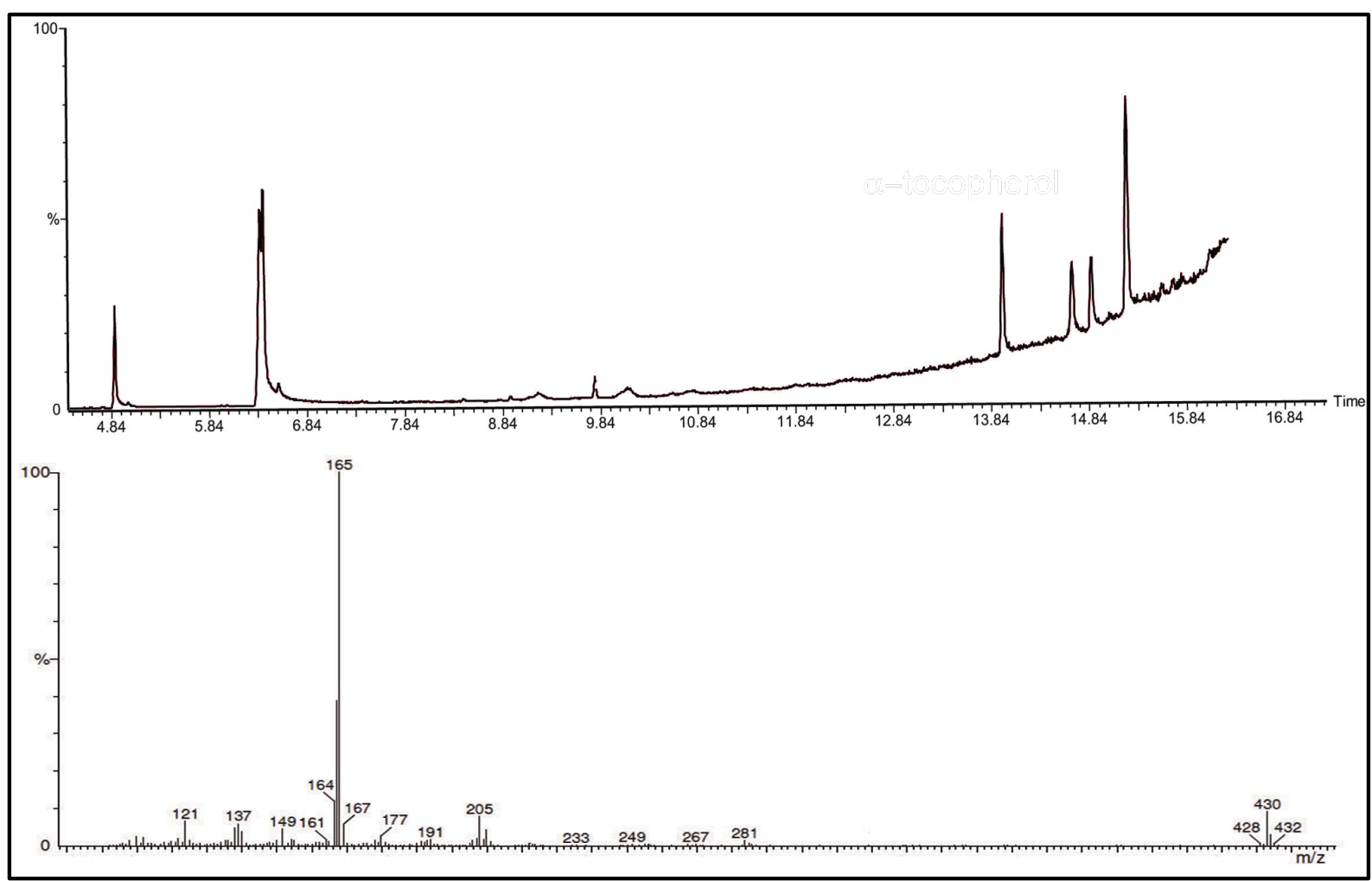

Fig 3: Chromatogram of the eluted sample from $20 \%$ sunflower oil labelled the peaks corresponding to $\alpha$-tocopherol (a). Mass spectrum of $\alpha$-tocopherol (b). 
Table 2: Quantities of $\alpha$-tocopherol from eluted samples from $20 \%$ of different vegetable oils (average of triplicate \pm standard deviation).

\begin{tabular}{|l|c|c|l|l|}
\hline Vegetable oil & $\begin{array}{c}\text { Quantity in spiked } \\
\text { oil solution }\left(\mathbf{m g ~ g}^{-1} \mathbf{)}\right.\end{array}$ & $\begin{array}{c}\text { Quantity in unspiked } \\
\text { oil solution }\left(\mathbf{m g ~ g}^{-1} \mathbf{)}\right.\end{array}$ & $\begin{array}{c}\text { Quantities in the } \\
\text { literature } \mathbf{( m g ~ g}^{-1} \mathbf{)}\end{array}$ & References \\
\hline Sunflower & $1.035 \pm 0.27$ & $0.277 \pm 0.08$ & $0.416-0.590$ & $3,17,21,43$ \\
\hline Wheat germ & $1.357 \pm 0.34$ & $0.298 \pm 0.06$ & $0.12-1.92$ & $14,16,17,41,43$ \\
\hline Olive & $1.027 \pm 0.82$ & $0.256 \pm 0.16$ & $0.10-0.530$ & $3,17,21,53,54$ \\
\hline Soybean & $1.313 \pm 0.60$ & $0.233 \pm 0.11$ & $0.0109-0.0143$ & 55,56 \\
\hline Palm & $0.946 \pm 0.21$ & $0.148 \pm 0.01$ & 0.0202 & 57 \\
\hline Sesame & $0.876 \pm 0.28$ & $\mathrm{Nd}^{*}$ & $0.03-0.7$ & 17 \\
\hline
\end{tabular}

* Not detected 


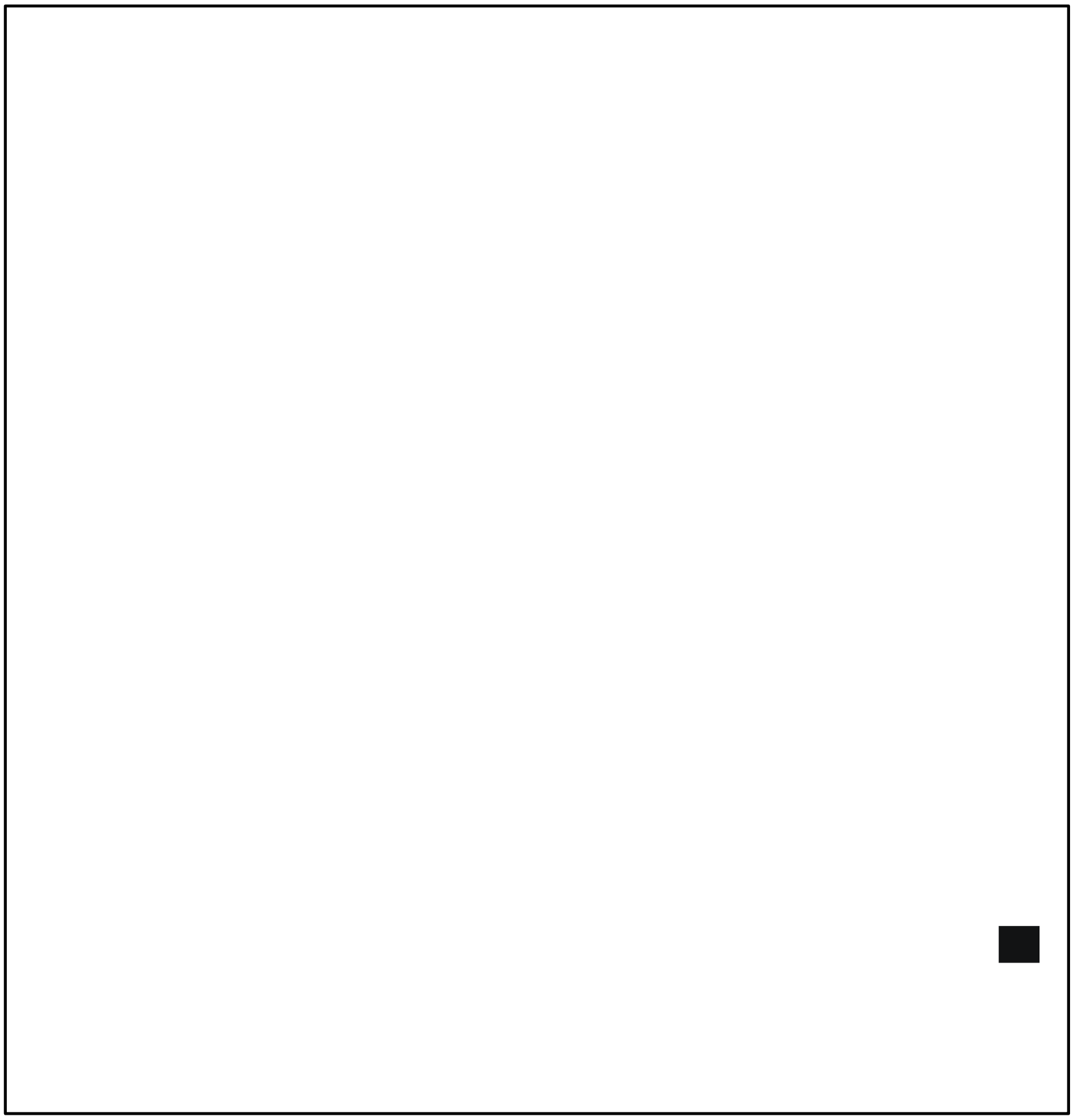

Fig 4: Chromatogram of sunflower oil labelled the peaks corresponding to phytosterols only (a). Mass spectrum of campesterol (b), stigmasterol (c), $\beta$-sitosterol (d). 
Table 3: Quantities of phytosterols from eluted samples of $20 \%$ of different vegetable oils (average of triplicate \pm standard deviation).

\begin{tabular}{|l|l|c|c|l|l|}
\hline Vegetable oil & Phytosterol & $\begin{array}{c}\text { Quantity in spiked } \\
\text { oil solution } \\
\left(\mathbf{m g ~ g}^{-1}\right)\end{array}$ & $\begin{array}{c}\text { Quantity in unspiked } \\
\text { oil solution } \\
\left(\mathbf{m g ~ g}^{-1}\right)\end{array}$ & $\begin{array}{l}\text { Quantities in } \\
\text { the literature } \\
\left(\mathbf{m g ~ g}^{-1}\right)\end{array}$ & References \\
\hline \multirow{5}{*}{ Sunflower } & Campesterol & $0.186 \pm 0.01$ & $0.058 \pm 0.03$ & $0.068-0.315$ & 17,19 \\
\cline { 2 - 6 } & Stigmasterol & $0.289 \pm 0.06$ & $0.146 \pm 0.03$ & $0.198-0.28$ & 17,19 \\
\cline { 2 - 6 } & $\beta$-sitosterol & $1.446 \pm 0.37$ & $0.741 \pm 0.19$ & $1.860-2.06$ & 17,19 \\
\hline \multirow{5}{*}{ Wheat germ } & Campesterol & $0.573 \pm 0.06$ & $0.489 \pm 0.16$ & $0.5-1.7$ & 17,33 \\
\cline { 2 - 6 } & Stigmasterol & $0.631 \pm 0.02$ & $0.307 \pm 0.14$ & Nd - 0.25 & 17,33 \\
\cline { 2 - 6 } & $\beta$-sitosterol & $2.285 \pm 0.41$ & $1.903 \pm 0.12$ & $2.5-6.2$ & 17,33 \\
\cline { 2 - 6 } & Campesterol & $0.242 \pm 0.01$ & $0.075 \pm 0.011$ & $0.059-0.3$ & 17,36 \\
\cline { 2 - 6 } & Stigmasterol & $0.409 \pm 0.28$ & $0.008 \pm 0.001$ & $0.015-1.0$ & 17,36 \\
\hline \multirow{3}{*}{ Soybean } & Campesterol & $0.344 \pm 0.04$ & $0.076 \pm 0.01$ & $0.82-1.20$ & 17,36 \\
\cline { 2 - 6 } & Stigmasterol & $0.956 \pm 0.29$ & $0.517 \pm 0.13$ & $0.28-0.824$ & $13,48,49$ \\
\cline { 2 - 6 } & $\beta$-sitosterol & $1.684 \pm 0.59$ & $1.398 \pm 0.24$ & $0.29-1.754$ & $33,56,57$ \\
\hline \multirow{3}{*}{ Palm } & Campesterol & $0.131 \pm 0.01$ & $0.074 \pm 0.01$ & 0.074 & 60 \\
\cline { 2 - 6 } & Stigmasterol & $0.266 \pm 0.10$ & $0.125 \pm 0.03$ & 0.022 & 3 \\
\cline { 2 - 6 } & $\beta$-sitosterol & $0.575 \pm 0.02$ & $0.299 \pm 0.10$ & 0.304 & 3 \\
\hline \multirow{3}{*}{ Sesame } & Campesterol & $0.457 \pm 0.21$ & $0.317 \pm 0.11$ & 0.1 & 17 \\
\cline { 2 - 6 } & Stigmasterol & $0.331 \pm 0.05$ & $0.220 \pm 0.09$ & 0.36 & 17 \\
\cline { 2 - 6 } & $\beta$-sitosterol & $2.380 \pm 0.30$ & $2.177 \pm 0.28$ & 3.1 & 17 \\
\hline
\end{tabular}




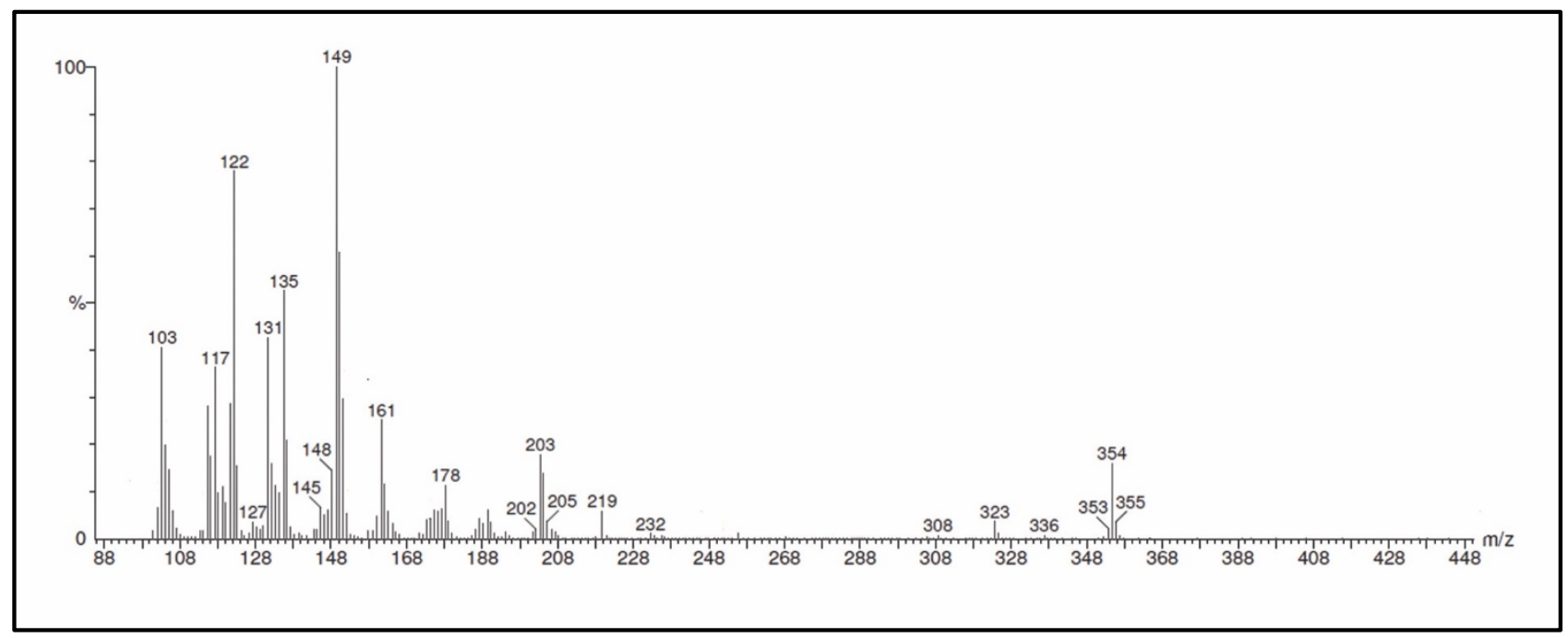

Fig 5: Mass spectrum of sesamin. 
Table 4: The matrix effects of spiking $1 \mathrm{~mL}$ heptane with standards solutions at known concentrations (percentage of recovery is average of triplicates \pm standard deviation).

\begin{tabular}{|l|c|c|}
\hline Standards of minor components & $\begin{array}{c}\text { Spiked concentration } \\
\left(\mu \mathrm{mL}^{-1}\right)\end{array}$ & Percentage of recovery \\
\hline Palmitic acid & 120 & $96 \pm 1$ \\
\hline Oleic and linoleic acid & 240 & $98 \pm 0.6$ \\
\hline $\boldsymbol{\alpha}$-tocopherol & 120 & $99 \pm 0.5$ \\
\hline campesterol & 19.2 & $74.6 \pm 2$ \\
\hline stigmasterol & 28.8 & $87.8 \pm 1.5$ \\
\hline $\boldsymbol{\beta}$-sitosterol & 55.2 & $91 \pm 1.6$ \\
\hline
\end{tabular}

